International Journal of Medical Sciences

ISSN 1449-1907 www.medsci.org 2007 4(4):209-215

Research Paper

CIvyspring International Publisher. All rights reserved

\title{
Inhibition by Natural Dietary Substances of Gastrointestinal Absorption of Starch and Sucrose in Rats 2. Subchronic Studies
}

\author{
Harry G. Preuss ${ }^{1}$, Bobby Echard ${ }^{1}$, Debasis Bagchi ${ }^{2}$, Sidney Stohs ${ }^{3}$ \\ 1. Georgetown University Medical Center, Department of Physiology, Washington, D.C. 20057, USA \\ 2. Department of Pharmacy Sciences, Creighton University Medical Center, Omaha, NE 68178, USA \\ 3. Advocare International, Carrollton, TX 75006, USA
}

Correspondence to: Harry G. Preuss M.D., Georgetown University Medical Center, Basic Science Bldg, Room 231B, 4000 Reservoir Rd, NW, Washington, D.C. 20057, USA

Received: 2007.03.01; Accepted: 2007.08.09; Published: 2007.08.10

Acute oral consumption of various natural inhibitors of amylase (bean and hibiscus extracts) and sucrase (L-arabinose) reduce absorption of starch and sucrose respectively in rats and pigs measured by lessened appearance of circulating glucose levels. The present subchronic study was designed to determine whether these selected inhibitors of gastrointestinal starch and sucrose absorption (so-called "carb blockers") remain effective with continued use and to assess their metabolic influences after prolonged intake. Sprague-Dawley rats were gavaged twice daily over nine weeks with either water or an equal volume of water containing a formula that included bean and hibiscus extracts and L-arabinose. To estimate $\mathrm{CHO}$ absorption, control and treated Sprague-Dawley rats were gavaged with either water alone or an equal volume of water containing glucose, rice starch, sucrose, or combined rice starch and sucrose. Circulating glucose was measured at timed intervals over four hours. The ability to decrease starch and sucrose absorption use. No toxic effects (hepatic, renal, hematologic) were evident. Blood chemistries revealed significantly lower circulating glucose levels and a trend toward decreased $\mathrm{HbA1C}$ in the nondiabetic rats receiving the natural formulation compared to control. Subchronic administration of enzyme inhibitors was also associated with many metabolic changes including lowered systolic blood pressure and altered fluid-electrolyte balance. We postulate that proper intake of natural amylase and sucrase inhibitors may be useful in the prevention and treatment of many chronic disorders associated with perturbations in glucose-insulin homeostasis secondary to the rapid absorption of refined CHO.

Key words: starch blockers, bean and hibiscus extracts, sucrose blockers, L-arabinose, hibiscus extract

\section{INTRODUCTION}

Excess consumption of refined, rapidly absorbed carbohydrates $(\mathrm{CHO})$ contributes to insulin resistance [1-3]. In turn, insulin resistance is associated with many troublesome, age-related perturbations including hypertension, dyslipidemias, diabetes, obesity and even premature aging [4-7]. Yudkin and associates [8-14] were among the first to promote the concept that table sugar was responsible in many cases for obesity and connected dysfunctions in insulin metabolism with many other aspects of the metabolic syndrome. While aging is associated with insulin resistance [15-17], insulin resistance may hasten the aging process - a vicious circle $[4,5,7]$. Suffice it to say, the most common experimental means to lengthen life span, caloric restriction, appears to work, at least in part, through its beneficial effects on the insulin system [18].

The many who believe that the excessive intake of refined $\mathrm{CHO}$ plays a major role in the development of insulin resistance have sought practical means to overcome this situation [19]. First, planned diets with low proportions of refined $\mathrm{CHO}$ have become popular. However, these diets do not satisfy everyone, and many concerns exist over the replacement of $\mathrm{CHO}$ with fats $[20,21]$. Second, refined $\mathrm{CHO}$ with their rapid absorption (high glycemic index) are more prone to cause insulin resistance than complex carbohydrates with slower absorption (low glycemic index). Addition of soluble fiber to the diet can slow absorption of refined $\mathrm{CHO}$, thus lowering the glycemic indices of foods and overcoming or ameliorating many of the adverse reactions resulting from increased refined $\mathrm{CHO}$ ingestion $[22,23]$. A third choice involves the use of natural dietary supplements that block and slow $\mathrm{CHO}$ absorption in the gastrointestinal tract.

The two primary purposes of the present investigation were (1) to determine whether selected inhibitors of gastrointestinal starch and sucrose absorption (carb blockers) remain effective with continued use and (2) to assess their metabolic effects after prolonged intake.

\section{METHODS AND PROCEDURES}

\section{Animals:}

The Animal Welfare Board at Georgetown University Medical Center approved this protocol for investigation. Sixteen Sprague-Dawley rats were 
obtained from Taconic Laboratories (Germantown, NY). Rats ate regular rat chow, drank water ad libitum, and were maintained in a facility with constant temperature and a 12 hour light-dark phase. Adult rats weighed between 402-558 grams at the start of the study.

\section{Protocols:}

Rats were gavaged twice daily with one gram (a total of two grams) of a formula containing various $\mathrm{CHO}$ blockers in four $\mathrm{ml}$ of water per day for nine weeks (test) or four $\mathrm{ml}$ of water alone (control) for nine weeks. There were eight rats in each group. In the fifth week, the regular drinking water was replaced with a $10 \% \mathrm{w} / \mathrm{v}$ sucrose solution. Systolic blood pressure (SBP) and body weight (BW) were measured weekly.

\section{Ingredients:}

The individual test ingredients as well as the formulation containing carb blockers were obtained from Advocare International, Carrollton, Texas ${ }^{1}$. The formulation was composed of $\mathrm{w} / \mathrm{w}$ : dry bean extract (seed - Phaseolus vulgaris) 19\%, hibiscus extract (flower - Hibiscus sabdariffa) 31\%, L-arabinose 31\%, gymnema extract ((leaf - Gymnema sylvestre) 12\%, green tea extract leaf - (Camellia sinensis) 6\%, and apple extract (fruit - Malus sylvestris) $1 \%$ plus the addition of Lactobacillus acidophilus and Bifidobacterium bifidum.

\section{Carbohydrate Tolerance Tests:}

After baseline blood was drawn, rats received either a gavage of two $\mathrm{ml}$ of water alone or two $\mathrm{g}$ rice starch, sucrose, glucose, or combined rice starch and sucrose in two $\mathrm{ml}$ of water. A drop of blood was obtained from the tail at baseline (time 0), 0.5 hour, 1 hour, 2 hours, 3 hours and 4 hours for glucose determination. Overall, less than $0.5 \mathrm{ml}$ of blood was obtained at one testing. Glucose was estimated using commercial glucose strips (Lifescan, One Touch Ultra, Melitas, CA).

\section{Miscellaneous Measurements}

SBP: SBP was measured by tail plethysmography using an instrument from Narco Biosciences (Houston, TX). This assay provided an indirect measure of SBP in conscious, slightly warmed rats [24]. In all studies, rats were allowed free access to their diet and water until SBP readings were obtained between $13.00 \mathrm{~h}$ and 17.00 $\mathrm{h}$. Readings on individual rats were taken 0.5-1 minute apart. To be accepted, SBP measurements on a given rat had to be virtually stable for at least three consecutive readings. In all studies, weekly readings were recorded.

BW: BW was estimated by routine scale measurements.

Blood Chemistries: Blood for chemical analysis was obtained at the end of the chronic protocol following removal of food four hours earlier. Biochemical analyses were performed by routine clinical procedures.

\footnotetext{
${ }^{1}$ Carb-Ease, Advocare International, Carrollton, TX
}

\section{Statistical Analyses}

Results are presented as mean \pm SEM. SBP and BW were examined by 2-way analyses of variance (one factor being group and the second factor being time of examination). Where a significant effect of regimen was detected by repeated measures ANOVA $(p<0.05)$, the Dunnett $t$ test was used to establish which differences between means reached statistical significance [25]. When the data from two columns of data were analyzed at a single time point, Student's $t$ test was used. Statistical significance was set at a $p<$ 0.05 .

\section{RESULTS}

The changes in body weight over the course of nine weeks were followed in eight rats gavaged daily with water (control) and eight rats gavaged daily with two grams of the formula containing carb blockers dissolved in a similar volume of water (test) (Fig. 1). The test group gained $46.5 \mathrm{~g} \pm 97.7(\mathrm{SEM})(10.4 \%)$ and the control group gained $68.3 \mathrm{~g} \pm 11.0(\mathrm{SEM})(14.9 \%)$ of body weight by the end of the nine weeks. The differences were not statistically significant $(p=0.12)$. SBP began to rise in the sixth week in the control rats, but decreased in the test rats after the fifth week (Fig. 2 ). The differences appeared after both groups were challenged with $10 \% \mathrm{v} / \mathrm{v}$ sucrose solution instead of regular drinking water. The differences in SBP values were statistically significant between the control and test groups over the last four weeks of study.

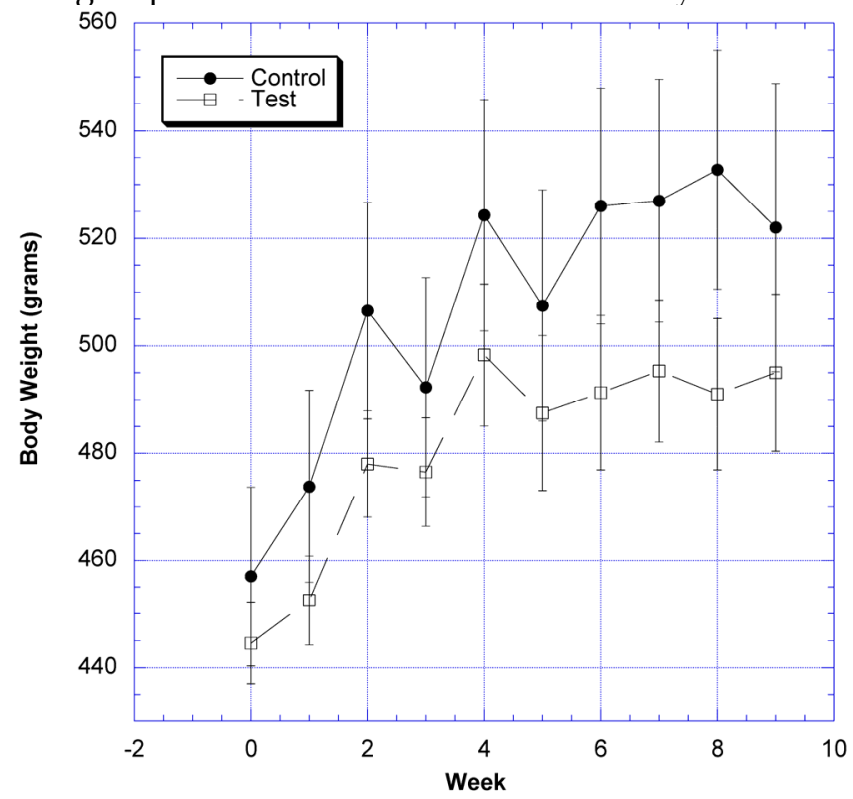

Fig. 1. The changes in body weight after daily challenges with water or two grams of the novel formulation dissolved in a similar volume of water is depicted. Mean \pm SEM shown for eight rats in each group. All rats drank a solution of $10 \% \mathrm{w} / \mathrm{v}$ sucrose in place of water from week 5 on

Between the seventh and ninth weeks of the subchronic study, the rats receiving the formula containing a variety of natural ingredients reputed to influence $\mathrm{CHO}$ absorption were individually 
challenged with rice starch (Fig. 3), sucrose (Fig. 4), glucose (Fig. 5), or a combination of sucrose and rice starch (Fig. 6) in the same manner as in the previous acute studies [26]. In the rats receiving the formula for 7-9 weeks, the appearance of blood glucose after the rice starch challenge was significantly lower, slightly more than one -half compared to control (Fig. 3). The area under the curve for the test rats was $61.0 \%$ of that for the control rats. Similarly, the appearance of circulating glucose after the sucrose challenge was also significantly less (Fig. 4). Area under the curve for the test group was $39.6 \%$ of control. When challenged directly with glucose (Fig 5), the circulating glucose levels after challenge in the test rats were similar to control with the exception of the fourth hour, when glucose levels were greater than control. Area under the curve for the test rats was $106.7 \%$ of control. When the rice starch and sucrose challenge were combined using the same concentrations that were given individually (Fig, 6), the appearance of circulating glucose over the first four hours was significantly lessened after gavage of the formula. The area under the curve for the test group was $49 \%$ of control.

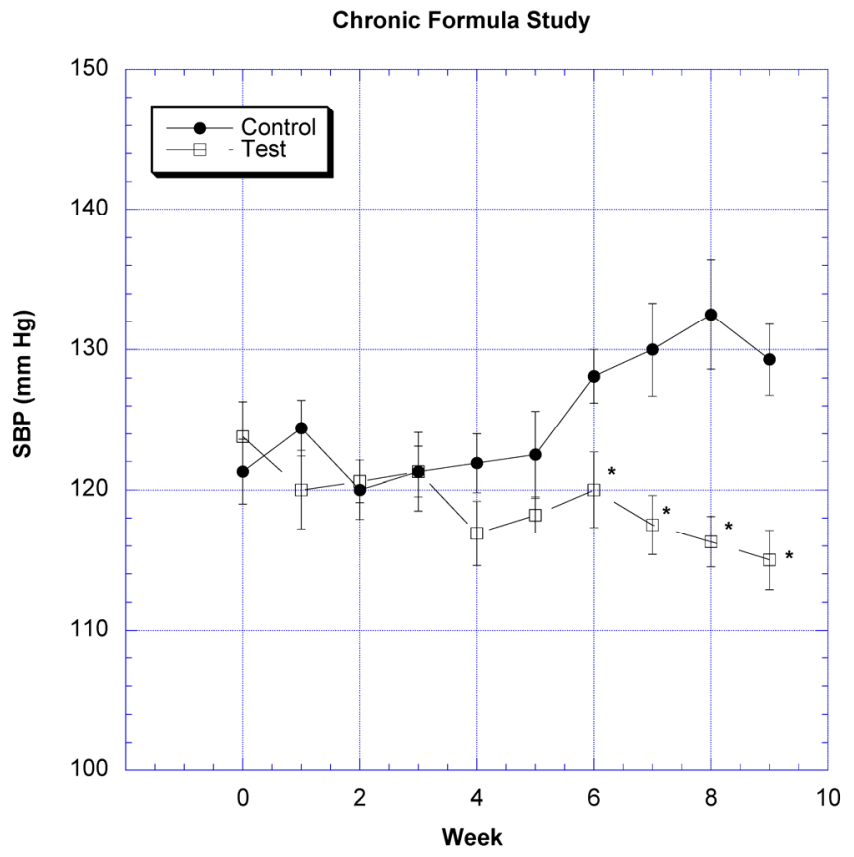

Fig. 2. The changes in systolic blood pressure (SBP) after daily challenges with water or two grams of the novel formulation dissolved in water is depicted. Mean \pm SEM shown for eight rats in each group. Rats drank a solution of $10 \% \mathrm{w} / \mathrm{v}$ sucrose in place of water from week 5 on. * Significantly different at that time point when compared to control.

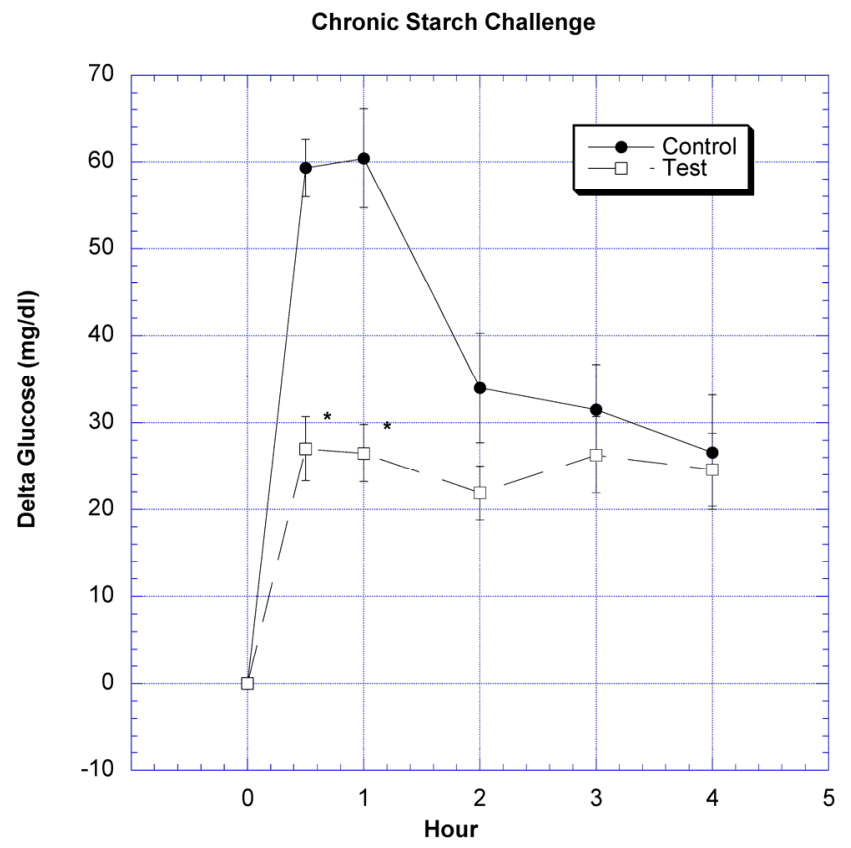

Fig. 3. Both groups of eight rats that had received water (control) or water plus two grams of the formulation (test) daily for six-nine weeks underwent a similar regimen as described in reference 26. On the day of study, instead of the usual daily gavage, they were gavaged acutely with two grams of rice starch. One-half hour prior to the $\mathrm{CHO}$ challenges and at the time of challenges a total of four $\mathrm{ml}$ of water was given to control, or two gram of formulation in four $\mathrm{ml}$ water was given to the test group. The change in circulating glucose at timed intervals after various challenges is depicted. Mean \pm SEM shown for eight rats in each group. * Significantly different at that time point when compared to control.

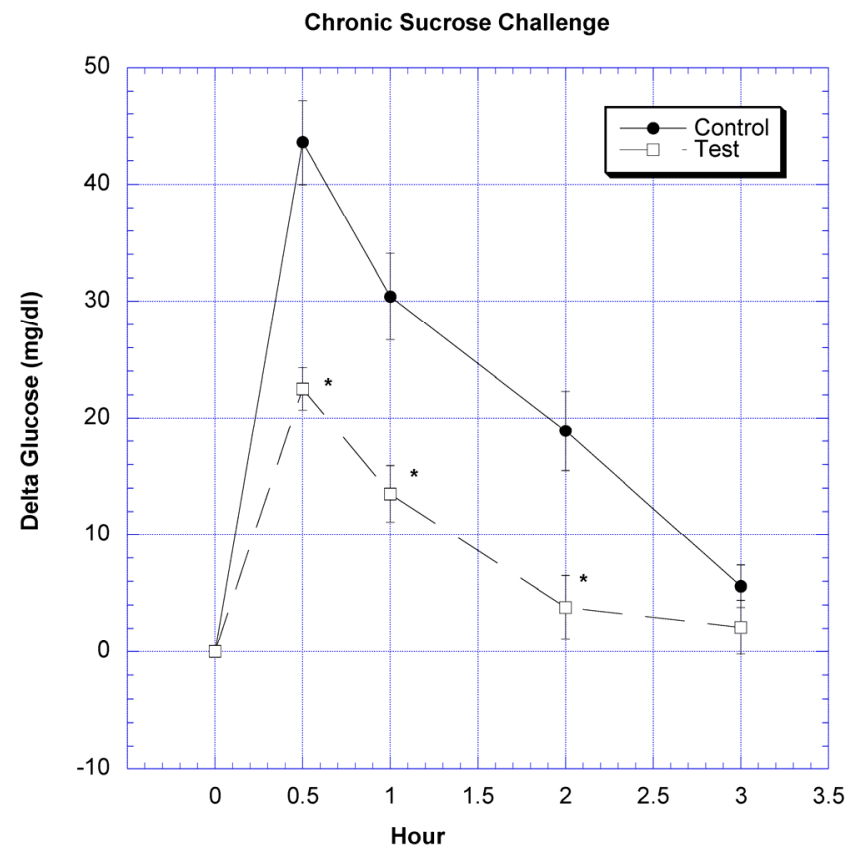

Fig. 4. Both groups of eight rats received a sucrose challenge. For details, see legend for Fig 3. 


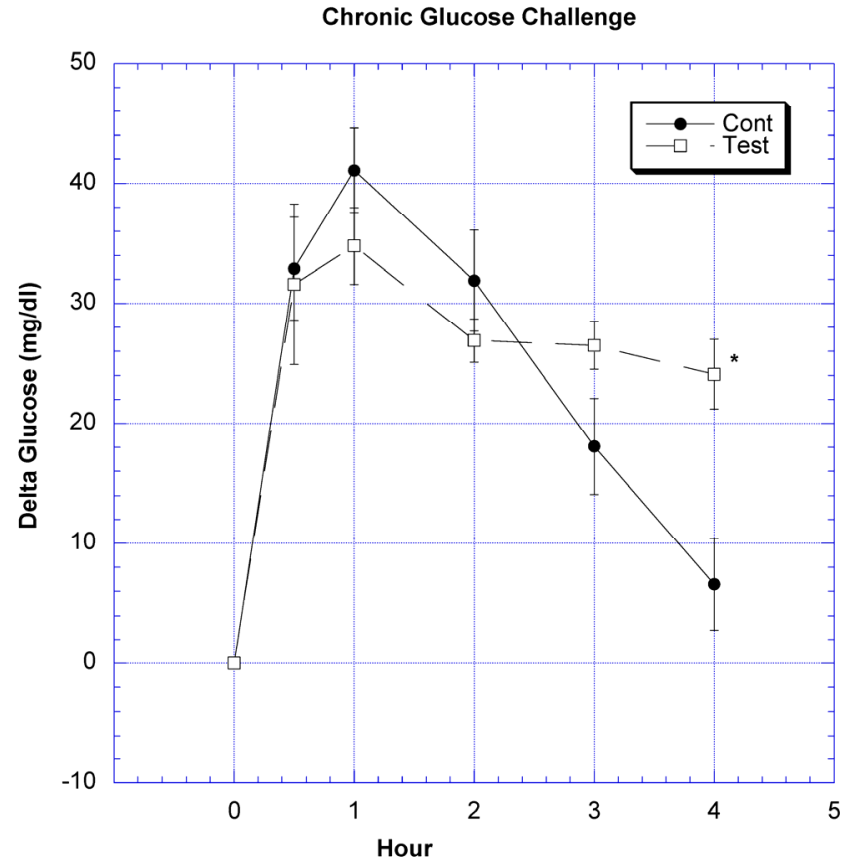

Fig. 5. Both groups of eight rats received a glucose challenge. For details, see legend for Fig 3.
Blood chemistries obtained during the last week of study (Table 1) comparing the test rats with the controls showed a statistically significant decrease in circulating concentrations of glucose, sodium, and chloride. The $29 \%$ decrease compared to control in HbA1C missed statistical significance but showed a trend $(p=0.082)$. Circulating potassium and total protein concentrations increased significantly in the test group. No other differences existed for all other blood chemistries measured in control and treated rats [Table 1]. White blood cell count (WBC), red blood cell count (RBC), hemoglobin (HGB), hematocrit (HCT) and platelet count between the two groups were not significantly different.

When the 24 hour intakes of food and water were examined at the end of studies (Fig 7), the mean daily food intake between groups was comparable -- $19.5 \mathrm{~g} \pm$ 0.9 (SEM) (control) vs. $18.7 \mathrm{~g} \pm 1.0$ (SEM) (test). However, there was a statistically significant difference in daily water intake between the two groups $-116.0 \mathrm{ml} \pm 3.1(\mathrm{SEM})$ (control) vs. $63.1 \mathrm{ml} \pm 5.8$ (SEM) (test) $(\mathrm{p}<0.0001)$.

Table 1 Blood Chemistries for Carb-Ease Study

\begin{tabular}{|c|c|c|c|}
\hline Parameter & Control & Carb-Ease & $\mathbf{p}$ \\
\hline Glucose $(\mathrm{mg} / \mathrm{dl})$ & $118.5 \pm 5.6$ & $101.9 \pm 4.5$ & $0.035^{*}$ \\
\hline BUN (mg/dl) & $19.3 \pm 0.9$ & $17.6 \pm 0.4$ & 0.125 \\
\hline Creatinine $(\mathrm{mg} / \mathrm{dl})$ & $0.45 \pm .02$ & $0.41 \pm .01$ & 0.123 \\
\hline Sodium (mEq/l) & $145 \pm 0.9$ & $141+0.9$ & $0.006^{*}$ \\
\hline Potassium (mEq/l) & $4.3 \pm 0.2$ & $5.2 \pm 0.1$ & $0.001^{*}$ \\
\hline Chloride (mEq/l) & $102.9 \pm 1.2$ & $98.8 \pm 1.1$ & $0.023^{*}$ \\
\hline $\mathrm{E} \mathrm{CO} 2(\mathrm{mEq} / \mathrm{l})$ & $34.5 \pm 1.7$ & $37.4+1.2$ & 0.188 \\
\hline Calcium (mg/dl) & $10.2 \pm .02$ & $10.1 \pm .03$ & 0.569 \\
\hline T Chol (mg/dl) & $92.0 \pm 6.5$ & $87.6+4.2$ & 0.581 \\
\hline Triglyc (mg/dl) & $94.6 \pm 18.9$ & $103.0 \pm 11.9$ & 0.713 \\
\hline T Protein (mg/dl) & $6.9 \pm 0.12$ & $7.3 \pm 0.08$ & $0.012^{*}$ \\
\hline Albumin (mg/dl) & $3.4+0.2$ & $3.5+0.07$ & 0.418 \\
\hline AST (unit/dl) & $132 . \pm 10.0$ & $121.4 \pm 9.1$ & 0.410 \\
\hline ALT (units/dl) & $46.9 \pm 4.6$ & $48.5 \pm 3.5$ & 0.779 \\
\hline Alk Phos (mg/dl) & $165 \pm 9.0$ & $182 \pm 6.7$ & 0.159 \\
\hline T Bilirubin (mg/dl) & $0.71 \pm .09$ & $0.84 \pm .13$ & 0.441 \\
\hline $\mathrm{HbA1C}$ & $3.03+.34$ & $2.34+.15$ & $0.082 \#$ \\
\hline
\end{tabular}




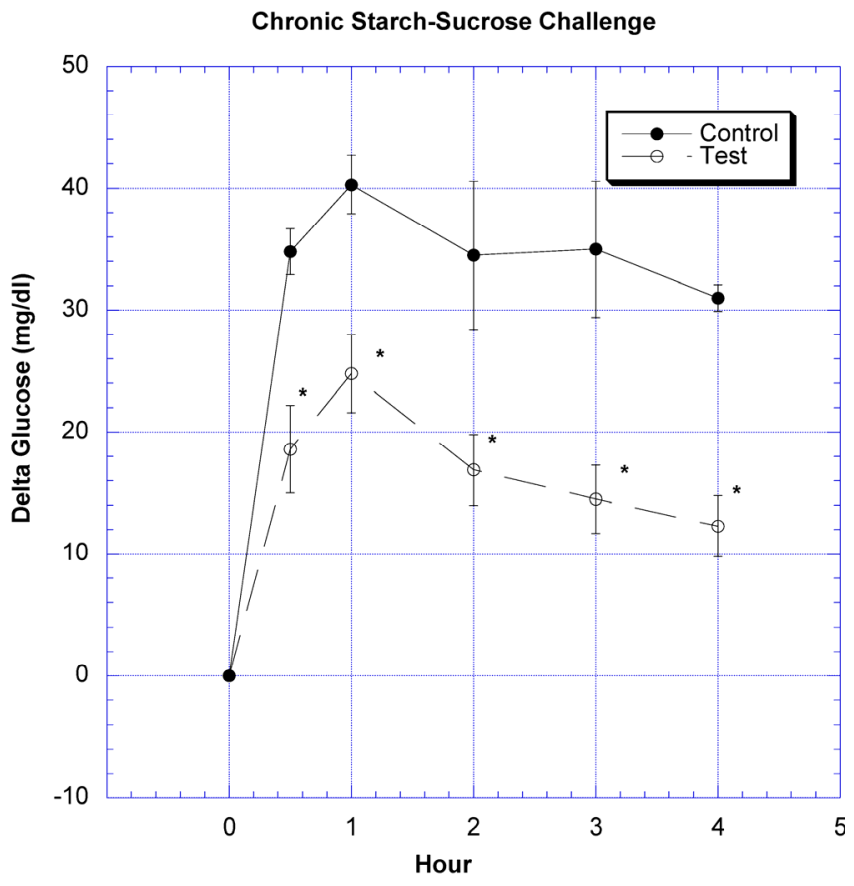

Fig. 6. Both groups of 8 rats received a combined rice starch $(2$ grams)-sucrose (2 grams) challenge. For details, see figure legend for Fig 3.

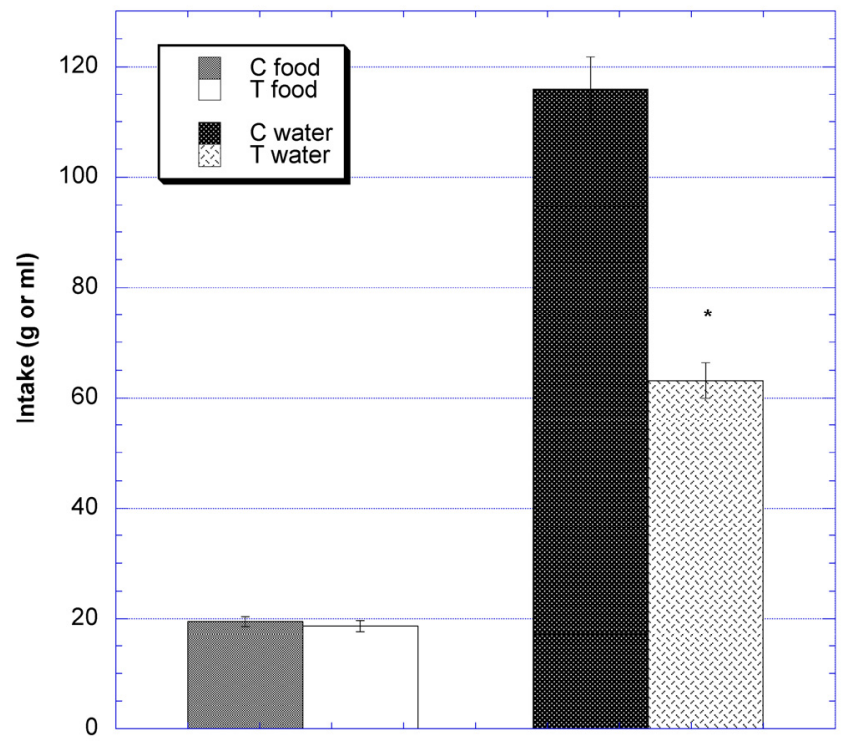

Fig 7. Twenty-four hour intake of food and water during the ninth week of the subchronic study. * Significantly different at that time point when compared to control. $\mathrm{N}=8$ in the control [C] and test $[\mathrm{T}]$ groups.

\section{DISCUSSION}

Our previous studies show that a formulation composed of inhibitors of the gastrointestinal absorption of starch and sucrose were effective at lessening their absorption in rats and pigs [26]. To determine whether the $\mathrm{CHO}$ blocking effects persisted, rats were followed for nine weeks with daily gavages of a formula containing so called starch and sucrose blockers. Over this time period, we found no significant changes in the rate of body weight gain compared to control, although there was a tendency to see a lower gain in the group receiving the formula. Continuation of this study might have resulted in a significant difference. When the drinking water was changed to $10 \% \mathrm{w} / \mathrm{v}$ sucrose in week 5, the systolic blood pressure (SBP) of the control rats began to rise, whereas the SBP of the test rats showed no such elevation. In our experience, changes in the SBP are a very sensitive marker of insulin sensitivity, i.e., a rise in SBP correlates with the development of insulin resistance [27]. The prevention of the blood pressure elevation suggests that the $\mathrm{CHO}$ blockers overcame the induction of insulin resistance brought on by refined $\mathrm{CHO}$

In the seventh through ninth week, the rats exposed daily to a combination of carb blockers received acute challenges of starch, sucrose and glucose in the same manner as the first acute studies [26]. After weeks of receiving the formula containing carb blockers, it was still able to lessen $\mathrm{CHO}$ absorption similar to that seen in the acute studies [26]. The utility of combining natural products containing inhibitors of both starch and sucrose absorption was strengthened when a combined starch-sucrose challenge, simulating a meal containing both, was influenced favorably by the novel formulation (Fig. 6).

In the previous acute study [26], we had not seen any effects on circulating glucose levels in rats receiving only $\mathrm{CHO}$ blockers with no $\mathrm{CHO}$ challenge. These results suggested that the $\mathrm{CHO}$ inhibitors were not working on overall $\mathrm{CHO}$ metabolism. Findings in the present study corroborate that opinion. Unlike the challenges with rice starch and sucrose, glucose challenge was not affected by the formulation of natural products, suggesting little direct effect on exogenous glucose absorption or endogenous metabolism (Fig. 5) [28]. The latter finding in vivo again supports an effect of the natural products on the enzymes amylase and sucrase rather than on glucose absorption or metabolism [29-37].

After nine weeks of daily intake of carb blockers, there was a significant lowering of circulating glucose levels in the test compared to the control rats. This finding is consistent with the trend to have lower circulating $\mathrm{HbA} 1 \mathrm{C}$ levels in rats consuming carb blocking formulation. Perhaps only a trend was seen In HbA1C levels, because the time of imbibing the sucrose solution was not long enough to produce large differences in the latter measurement.

The decrease in serum sodium and chloride concentrations coinciding with the increase in potassium levels suggests an effect of the formula on the renin-angiotensin-aldosterone system [38]. Because angiotensin 2 can influence water intake [39], a decrease in circulating angiotensin 2 might explain, at least in part, both the lower water intake and the decrease in SBP. Dietary CHO have long been known to influence hormonal systems such as the renin-angiotensin-aldosterone and catecholamine 
systems $[40,41]$.

These results support the hypothesis that $\mathrm{CHO}$ blockers like those examined in the present investigation will theoretically lower glycemic indices of various foods. Their activity continues even after weeks of constant intake. Further studies are needed to determine these ingredients will have a significant role in the therapy of various facets of the metabolic syndrome -- including the aging process.

\section{ACKNOWLEDGMENT}

The investigation was supported with funds from Advocare International of Carrollton, Texas. Dr Preuss is a member of the Sci-Med Advisory Board, and Dr Stohs is the Senior Vice President for Research and Development of Advocare International.

\section{CONFLICT OF INTEREST}

The authors have declared that no conflict of interest exists.

\section{REFERENCES}

1. Pawlak DB, Kushner JA, Ludwig DS. Effects of dietary glycaemic index on adi-posity, glucose homeostasis, and plasma lipids in animals. Lancet 2004; 364:778-785.

2. Brehm BJ, Seeley RJ, Daniels SR, D'Allessio DA. A randomized trial comparing a very low carbohydrate diet and a calorie-restricted low fat diet on body weight and car-diovascular risk factors in healthy women. J Fam Pract 2003; 52:515-516.

3. Meckling KA, Gauthier M, Grubb R, Sanford J. Effects of a hypocaloric, low carbohydrate diet on weight loss, blood lipids, blood pressure, glucose tolerance, and body composition in free-living overweight women. Canad J Physiol Pharmacol 2002; 80:1095-1105.

4. DeFronzo R. Glucose intolerance and aging. Diabetes Care 1981; 4:493-501.

5. Preuss HG. Effects of glucose/insulin perturbations on aging and chronic disor-ders of aging: the evidence. J Am Coll Nutr 1997; 16:397-403.

6. DeFronzo RA, Ferinimmi E. Insulin resistance: a multifaceted syndrome respon-sible for NIDDM, obesity, hypertension, dyslipidemia, and atherosclerotic cardiovascular disease. Diabetes Care 1991; 14:173-194.

7. Preuss HG, Bagchi D, Clouatre D. Insulin resistance; a factor in aging. In: Ghen MJ, Corso N, Joiner-Bey H, Klatz R, Dratz A, eds. The Advanced Guide to Longevity Medicine. Landrum SC: Ghen. 2001: 239-250,.

8. Yudkin J, Morland J. Sugar intake and myocardial infarction. Am J Clin Nutr 1964; 20:503-506.

9. Yudkin J. Patterns and trends in carbohydrate consumption and their relation to disease. Proc Nutr Soc 1964; 23:149-162.

10. Szanto S, Yudkin J. The effect of dietary sucrose on blood lipids, serum insulin, platelet adhesiveness, and body weight in human volunteers. Postgrad Med J 1969; 45:602-607.

11. Yudkin J, Szanto SS. Hyperinsulinemia. Br Med J 1971; 1:349.

12. Yudkin J. Sugar and disease. Nature 1972; 239:197-199.

13. Yudkin J. Sugar and obesity. Lancet 1983; 2:794.

14. Yudkin J. Sucrose, coronary heart disease, diabetes, and obesity. Do hormones provide a link? Am Heart J 1988; 115:493-498.

15. Reaven GM, Chen N, Hollenbeck C, Chen YDI. Effect of age on glucose toler-ance and glucose uptake in healthy individuals. J Am Ger Soc 1989; 37:735-740.

16. Broughton DL, Taylor RL. Review: deterioration of glucose tolerance with age: the role of insulin resistance. Age and Aging $1991 ; 20: 221-225$.
17. Shimokata H, Muller DC, Fleg JL, Sorkin J, Ziemba AW, Andres R. Age as inde-pendent determinant of glucose tolerance. Diabetes 1991; 40:44-51.

18. Masoro EJ, McCarter RJM, Katz MS, McMahan CA. Dietary restriction alters characteristics of glucose fuel use. J Gerontology 1992; 47:B202-B208.

19. Reiser S, Handler HB, Gardner LB, Hallfrisch JG, Michaelis OE, Prather ES. Iso-caloric exchange of dietary starch and sucrose in humans. II. Effect on fasting blood insu-lin, glucose, and glucagon and on insulin and glucose response to a sucrose load. Am J Clin Nutr 1979; 32:2206-2216.

20. Riley MD, Coveney J. Atkins and the new diet revolution: is it really time for re-gimen change? Weight loss occurs in the short term, but not enough is known to recom-mend long term use. Med J Aust 2004; 181:526-527.

21. No author: Is the Atkins diet on to something? No, it's not a healthy way to eat. But the high-protein, low-carbohydrate diet may hold a few important lessons about weight loss and healty eating. Harv Health Lett 2003; 28:1-2.

22. Wolf BW, Wolever TM, Lai CS, Bolognesi C, Radmard R, Maharry KS, Garleb KA, Hertzler SR, Firkins JL. Effects of a beverage containing an enzymatically induced-viscosity dietary fiber, with or without fructose, on the postprandial glycemic response to a high glycemic index food in humans. Eur J Clin Nutr. 2003; 57:1120-1127.

23. Zein M, Areas J, Knapka J, Gleim G, DiPette D, Holland B, Preuss HG. Influ-ence of oat bran on sucrose-induced blood pressure elevations in SHR. Life Sci 1990; 47:1121-1128.

24. Bunag RD. Validation in awake rats of a tail-cuff method measuring systolic pressure. J Appl Physiol 1973; 34:279-282.

25. Dunnett C. A multiple comparison procedure for comparing several treatments with control. J Am Statis Assoc 1955; 50:1096-1121.

26. Preuss HG, Echard B, Bagchi D, Stohs S. Inhibition by Natural Dietary Substances of Gastrointestinal Absorption of Starch and Sucrose in Rats and Pigs: 1. Acute Studies. Int J Med Sci 2007; 4:196-202

27. Preuss HG, Gondal JA, Bustos E, Bushehri N, Lieberman S, Bryden NA, Po-lansky MM, Anderson RA. Effect of chromium and guar on sugar-induced hypertension in rats. Clin Neph $1995 ; 44: 170-177$.

28. Cori CF. The fate of sugar in the animal body. I. The rate of absorption of hexoses and pentoses from the intestinal tract. J Biol Chem 1925; 66:691-715.

29. Udani J, Hardy M, Madsen DC. Blocking carbohydrate absorption and weight loss: a clinical trial using Phase 2 brand proprietary fractionated white bean extract. Al-tern Med Rev 2004; 9:63-69.

30. Santimone M, Koukiekolo R, Moreau Y, Le Berre V, Rouge P, Marchis-Mouren G, Desseaux V. Porcine pancreatic alpha-amylase inhibition by the kidney bean (Phaseo-lus vulgaris) inhibitor (Alpha-AII) and structural changes in the alpha-amylase inhibitor complex. Biochim Biophys Acta 2004; 1696:181-190.

31. Frels JM, Rupnow JH. Purification and partial characterization of two alpha-amylase inhibitors from black bean (Phaseolus vulgaris). J Food Biochem 1984; 1:385-401.

32. Gibbs B, Alli I. Characterization of a purified alpha-amylase inhibitor from white kidney bean (Phaseolus vulgaris). Food Research International. 1998; 31:217-225.

33. Hansawasdi C, Kawabata J, Kasai T. Alpha-amylase inhibitors from roselle (Hi-biscus sabdariffa Linn.) tea. Biosci Biotechnol Biochem 2000; 64:1041-1043.

34. Hansawadi C, Kawabata J, Kasai T. Hibiscus acid as an inhibitor of starch diges-tion in the Caco-2 cell model system. Biosci Biotechnol Biochem 2001; 65:2087-2089.

35. Seri K, Sanai K, Matsuo N, Kawakubo K, Xue C, Inoue S. 
L-arabinose selec-tively inhibits intestinal sucrase in an uncompetitive manner and suppresses glycemic re-sponse after sucrose ingestion in animals. Metabolism 1996; 45:1368-1374.

36. Osaki S, Kimura $T$, Sugimoto $T$, Hizukuri $S$, Iritani $N$. $\mathrm{L}$-arabinose feeding pre-vents increases due to dietary sucrose in lipogenic enzymes and triacylglycerol levels in rats. J Nutr 2001; 131:796-799.

37. Brudnak MA. Weight-loss drugs and supplements: are there safer alternatives? Medical Hypotheses 2002; 58:28-33

38. Shi S-J, Preuss HG, Abernathy DR, Li X, Jarrell ST, Andrawis NS. Elevated blood pressure in spontaneously hypertensive rats consuming a high sucrose diet is asso-ciated with elevated angiotensin II and is reversed by vanadium. J Hyper 1997; 15:857-862.

39. Skott O. Angiotensin II and control of sodium and water intake in the mouse. Am J Physiol Regul Integr Comp Physiol. 2003; 284:R1380-1381.

40. Krieger DR, Landsberg L. Mechanisms in obesity-related hypertension: role of insulin and catecholamines. Am J Hyper 1988; 1:84-90.

41. Fournier RD, Chiueh CC, Kopin IJ, Knapka JJ, DiPette D, Preuss HG. The inter-relationship between excess $\mathrm{CHO}$ ingestion, blood pressure and catecholamine excretion in SHR and WKY. Am J Physiol 1986; 250:E381-385. 